\title{
ATUALIDADES E PERSPECTIVAS DAS ANONÁCEAS NO MUNDO ${ }^{1}$
}

\author{
ABEL REBOUÇAS SÃO JOSÉ ${ }^{2}$, MÔNICA DE MOURA PIRES ${ }^{3}$ \\ AFONSO LÚCIO GOMES ESTRELA DE FREITAS ${ }^{4}$, DENIS PEREIRA RIBEIRO ${ }^{5}$ \\ LUIS ALFONSO AGUILAR PEREZ
}

RESUMO -Várias espécies da família Annonaceae produzem frutos comestíveis cultivados em pomares comerciais ou coletados de forma extrativista, em diversas partes do mundo. O gênero Annona possui elevado número de espécies nativas, no entanto poucas produzem frutos comestíveis. Algumas são cultivadas comercialmente, outras são obtidas de forma extrativista. As principais anonáceas cultivadas no mundo são: Annona muricata, Annona squamosa e Annona cherimola, com destaque também para a atemoia (híbrido entre A. squamosa x A. cherimola). Economicamente, são importantes para muitos países da África, Ásia e também da América Central, do Norte e do Sul. Os principais países produtores são: Austrália, Chile, Espanha, Estados Unidos, Nova Zelândia e Israel para cherimólia; México, Brasil, Venezuela e Costa Rica para graviola; e Índia, Brasil, Tailândia, Filipinas e Cuba para pinha. A produtividade de frutos das anonáceas nos diversos países produtores é relativamente baixa, em função do uso inadequado de técnicas de manejo (irrigação, fertilização, podas, polinização, controle de insetos e enfermidades, etc.). No Brasil, os cultivos comerciais mais relevantes com anonáceas são: pinha (A. squamosa L.), graviola (A. muricata L.) e atemoia. O objetivo deste trabalho é apresentar a situação atual e as perspectivas para as anonáceas no Brasil e no mundo. O cultivo é caracteristicamente de pequenos agricultores, usando especialmente a mão de obra familiar. De um modo geral, esses cultivos apresentam relevância socioeconômica nos países que possuem produção comercial pela geração de emprego e renda, e vêm, recentemente, ganhando importância no mercado mundial, dada sua condição de fruta exótica e pela sua qualidade, dentre as quais o valor nutracêutico (vitaminas, antioxidantes e outras propriedades funcionais). A expansão do consumo e sua maior relevância no mercado mundial dependem de ações relativas à divulgação do produto por meio de um programa de marketing, demonstrando suas qualidades nutricionais e funcionais para a saúde dos consumidores.

Termos de indexação: Annona, produção, consumo, mercado, países produtores.

\section{ACTUALITY AND PERSPECTIVES OF ANNONACEOUS IN THE WORLD}

\begin{abstract}
Several species of Annonaceae family produce edible fruit. They are cultivated in commercial orchards or collected in an extractivism way in different parts of the world. The Annona genus has many species, but only a few of them are edible. Among them only a few ones are commercially cultivated, the most important economically are: (soursop) Annona muricata, (custard apple) Annona squamosa and Annona cherimola (cherimoya) especially; atemoya (hybrid between A. squamosa $x$ A. cherimola) also presents in increasing importance. They are important economically for many countries in Africa, Asia and America (Central, North and South). The main producing countries are: cherimoya production in Australia, Chile, Spain, the United States, New Zealand and Israel in soursop; Mexico, Brazil, Venezuela and Costa Rica in custard apple: India, Brazil, Thailand, Philippines and Cuba. Fruit yield of Annonaceae in several producing countries is relatively low, due to the inappropriate use of management techniques (irrigation, fertilization, pruning, pollination, insect and disease control, etc.). In Brazil, the most important commercial crops with Annonaceae are: custard apple, soursop and atemoya. The objective of this study is to present the current status and perspectives for the Annonaceae in Brazil and worldwide. The cultivation is characterized mainly by small farmers, especially using the family labor. In general it can be considered that this group of fruits presents increasing important socio-economic values within the producing countries, but considering international market it recently presents more and more importance, because of their status as exotic fruit showing excellent qualities, including the functional value, such as vitamins, antioxidants and other functional properties. The increase in consumption of Annonaceae may be intensified if the producing countries implement an aggressive marketing program demonstrating its nutritional and functional qualities for consumers' health. Index terms: Annona, production, consumption, market, producing countries.
\end{abstract}

\footnotetext{
${ }^{1}$ Palestra Anonáceas - V Congresso Internacional \& Encontro Brasileiro sobre Annonaceae: do gene à exportação (19 a 23 de Agosto de 2013). Botucatu-SP.

${ }^{2}$ UESB/DFZ, Est. do Bem Querer Km 4, CEP 45.083-900, Vit. da Conquista-BA. E-mail: abeljose3@gmail.com.

${ }^{3} \mathrm{UESC} / \mathrm{DCEC} / \mathrm{MERPP}$, Rod. Jorge Amado km 16, Ilhéus-BA. E-mail: mpires@uesc.br

${ }^{4}$ IDAF-ES, Vitória-ES. E-mail: afonsoestrela@hotmail.com

${ }^{5}$ UESB/DFZ, Est. do Bem Querer Km 4, CEP 45.083-900, Vit. da Conquista-BA. E-mail: denisprd3@hotmail.com

${ }^{6}$ Colegio de Postgraduados, México. Email: aguilar.luis@colpos.mx
} 


\section{INTRODUÇÃO}

Várias espécies da família Annonaceae produzem frutos comestíveis cultivados em pomares comerciais ou coletados de forma extrativista, em diversas partes do mundo. Na literatura, são relatados 119 gêneros e mais de 2.000 espécies da família Annonaceae nas zonas tropicais do novo e velho mundo, e poucos gêneros presentes em zonas de clima temperado. O gênero Annona possui 118 espécies, das quais 108 são originárias da América Tropical e 10 da África Tropical, e apenas uma espécie (Annona glabra) é relatada nesses dois continentes. Das 13 espécies que produzem frutos comestíveis, 9 são cultivadas, 5 possuem maior importância econômica, sendo que, dessas, três se destacam no mercado: Annona muricata, Annona squamosa e Annona cherimola (Quadro 1).

Muitas outras espécies são cultivadas em maior ou menor escala em diversas partes do mundo, podendo citar como exemplo: A. diversifolia (Ilama) no México, Guatemala e outros países da América Central.

A origem da palavra Annona é do latim e significa "colheita anual". Para muitos países da África e Ásia e também da América Central, do Norte e do Sul, as anonáceas são importantes economicamente. Em geral, seu consumo restringe-se ao mercado interno (local e/ou regional) e raramente seus frutos são exportados, apesar de seu potencial. Como outras fruteiras tropicais, elas podem ser consideradas plantas de multiuso decorrente de seu valor nutricional como produto alimentar. Habitualmente, são comercializadas sob a forma de fruta fresca, polpa fresca ou congelada, sendo ainda utilizadas no preparo de sucos, geleias, iogurtes, sorvetes, entre outras finalidades alimentares.

Os países produtores que mais se destacam no mercado das anonáceas são: Austrália, Chile, Espanha, Estados Unidos, Nova Zelândia e Israel, para cherimólia; México, Brasil, Venezuela e Costa Rica, para graviola; e Tailândia, Filipinas, Brasil, Cuba e Índia, para pinha.

Além disso, as espécies de anonáceas são consideradas de fácil adaptabilidade a diferentes condições edafoclimáticas, e algumas espécies comportam-se bem em clima quente e úmido das zonas tipicamente tropicais, apresentando bons índices de produtividade, sendo cultivadas comercialmente em diversas partes do mundo pela rentabilidade alcançada.

No Brasil, encontram-se inúmeras espécies em diversas regiões. Nos cerrados brasileiros, norte de Minas Gerais e oeste da Bahia, é comum encontrar
Annona crassiflora (marolo) e Annona coriacea (araticum), e apesar de não existirem cultivos comerciais, os frutos dessas duas espécies são colhidos extrativamente e comercializados em centros consumidores locais e, muitas vezes, obtêm preços remuneradores. Essas e muitas outras espécies, pelo potencial econômico que apresentam, podem ser cultivadas regionalmente e atender a nichos de consumidores; no entanto, para atingir novos mercados, necessitam ser cultivadas e, para tanto, são necessários programas de melhoramento genético, hibridações intra ou interespecíficas, técnicas de manejo adequado das plantas, colheita e pós-colheita em função das exigências do mercado consumidor. No semiárido do Nordeste brasileiro é comum encontrar diversas espécies de anonáceas nativas, sem identificação. Nas margens do Rio São Francisco, próximo ao município de Ibotirama, na Bahia, há uma espécie que apresenta fruto pequeno e amarelo, quando maduro, e planta com altura entre 2 e 3 metros, de boa adaptabilidade à seca. Em períodos de grande estiagem, a planta perde suas folhas para suportar essa condição adversa. Nos municípios de Anagé e Caraíbas, localizados no semiárido baiano, são encontradas plantas com alturas superiores a 8 metros, que ficam completamente desfolhadas na época de seca. Além dessas espécies silvestres citadas, existem inúmeras, dispersas no território brasileiro.

No Brasil, os cultivos comerciais mais relevantes são de graviola ( $A$. muricata L.) e pinha ( $A$. squamosa L.). Recentemente, têm-se expandido os cultivos de atemoia e cherimólia, que são espécies introduzidas no País em meados da década de 1980. No CEAGESP, as anonáceas mais comercializadas são pinha, atemoia e graviola (Tabela 1). Nos Estados de São Paulo, Minas Gerais e Paraná, a área plantada e a produção de atemoia têm aumentado de forma relevante nos últimos anos.

É crescente no Brasil o consumo de frutas do grupo das anonáceas, embora a oferta interna ainda seja insuficiente, pois a produção nacional não se apresenta bem consolidada, o que significa que ainda há espaço no mercado a ser conquistado (SOBRINHO, 2010). Para isso, é necessário um acompanhamento sistemático do mercado, da demanda e das exigências do consumidor, além de organização da cadeia produtiva, em especial na adoção de práticas recomendadas de colheita, pós-colheita, transporte e distribuição, que contribuam para padrões de maior qualidade e competitividade das frutas (NOGUEIRA et al., 2005).

Em geral, o mais comum é observar-se o cultivo de anonáceas em pequenas propriedades rurais, por ser intensiva no uso de mão de obra em todas 
as fases da cultura. Para regiões com aptidão, forte presença de produtores familiares e/ou mão de obra qualificada, o cultivo da graviola abre perspectivas de diversificação de cultivos e ganhos de mercado.

\section{O MERCADO DA GRAVIOLA}

Segundo Ramos et al. (2001), a gravioleira faz parte de um grupo de frutíferas de importância econômica em diversos países, como Venezuela, Colômbia, Porto Rico, Costa Rica, México, Panamá, Jamaica, Cuba, Espanha, Índia, Honduras, Guiana, Suriname, Brasil, Peru, Senegal e Cingapura.

As maiores superfícies de área plantadas no mundo encontram-se, por ordem de relevância, no México, Brasil, Venezuela e Costa Rica. No México, a produção em nível nacional foi de $20.050,14$ t no ano de 2011, com uma área total plantada de 2.400 ha (1.944 ha de sequeiro) e uma superfície colhida de 2.335 ha. O Estado de Nayarit ocupa o primeiro lugar em área cultivada, com 1.596,85 ha de sequeiro e uma produção de $14.960 \mathrm{t}$, com produtividade média de 9,22 t ha ${ }^{1}$. Esse Estado representa mais de $80 \%$ do total da área cultivada de sequeiro no México, em 2011. Nos últimos anos, o cultivo de gravioleira tem apresentado um interesse crescente por parte dos produtores mexicanos em função dos preços e da demanda que a fruta vem alcançando. A área cultivada em condições de sequeiro cresceu entre 2003 a 2011, em $23,9 \%$ (Tabela 2). A produtividade média do país em 2011 foi de 8.58 t ha $^{-1}$ (SIAP-SAGARPA, 2013).

Os cenários traçados para a cultura é de expansão das exportações, especialmente para países da América do Norte, Caribe, Ásia e Austrália, muito embora alguns fatores relativos ao cultivo possam restringir ou limitar o crescimento desse mercado, especialmente relativos à produção, como baixa produtividade atribuída a problemas de polinização, ataques de pragas e doenças, e problemas no manejo pós-colheita.

A área cultivada irrigada no México foi de 456 ha em 2011 e, ao longo de 2003 a 2011, observou-se um incremento da área plantada de $16,75 \%$. Apesar do uso de irrigação, observa-se, nos diversos estados produtores desse país, que não houve incremento tecnológico, pois a produtividade não aumentou (média de $8,56 \mathrm{t} \mathrm{ha-}^{1} \mathrm{em} 2011$ ), quando comparada às áreas de sequeiro (média de 8,58 t ha- ${ }^{1}$ ), essa é uma situação observada ao longo do período de 2003 a 2011, que certamente ocorre em função de manejo técnico empregado nos pomares e das condições edafoclimáticas.

No Brasil, atualmente o segundo maior produtor de graviola do mundo, observou-se que, a partir de meados da década de 1990, essa fruta passou a ter maior destaque entre as frutas tropicais brasileiras, pela sua boa aceitação no mercado nacional, tanto por parte do consumidor como por parte das indústrias de processamento de polpa. Seu cultivo está presente de forma economicamente relevante nas regiões Norte, Nordeste, Centro-Oeste e Sudeste, destacando-se os Estados da Bahia, Alagoas, Ceará, Paraíba, Pernambuco e Pará (LIMA, 2004).

Apesar da escassez de dados sobre área plantada e comercialização da graviola, sabe-se que há expansão dos plantios, no Brasil nos últimos anos cinco, especialmente no Estado da Bahia, maior produtor nacional, cuja área plantada georreferenciada foi de 1.300 ha (ADAB, 2010), e deve ultrapassar 2.000 ha em 2013. Em 2010, a Agência de Defesa Agropecuária da Bahia (ADAB) estimou em 8 mil toneladas a produção de graviola, com perspectivas de crescimento em função do aumento nas áreas plantadas no Estado. Tal condição levará a Bahia a ocupar a posição de maior produtor mundial quando todas essas áreas estiverem em plena produção.

O cultivo comercial da gravioleira ainda é recente; entretanto, sua importância socioeconômica tem aumentado nos últimos anos em função do aumento da demanda por frutas tropicais, além da possibilidade de uso na indústria farmacêutica e de cosméticos. Esse interesse pelo cultivo de anonáceas deve-se ao preço remunerador alcançado no mercado (SOBRINHO, 2010). Esse novo panorama vem levando a transformações no mercado, pois antigamente os frutos eram destinados, na quase totalmente, à agroindústria para obtenção de polpa, suco, néctar e outros. Atualmente, importante quantidade da produção é comercializada sob a forma de fruta fresca. Dados da Central de Abastecimento de Salvador, no Estado da Bahia, apontam que a comercialização de graviola como fruta fresca cresceu cerca de $350 \%$ entre 2005 e 2011 (EBAL, 2011).

De modo geral, o nível tecnológico adotado pela maioria dos produtores de graviola é muito diferenciado. Muitos produtores não utilizam tecnologia moderna, como irrigação, nutrição adequada, poda, polinização artificial, proteção dos frutos e manejo de pragas, limitando o potencial do cultivo e comprometendo a produtividade e a qualidade dos frutos produzidos. Entretanto, há muitos pomares onde a produção é amparada por grande aporte tecnológico, garantindo elevada produtividade e, consequentemente, rentabilidade financeira ao agricultor.

A expansão do cultivo de graviola enfrenta muitas limitações relacionadas ao manejo técnico das plantas dentro dos pomares, em função da escassez de informações técnicas, especialmente sobre o manejo 
integrado de pragas, irrigação, nutrição mineral, dentre outros. Assim, é fundamental e necessária a busca por novos resultados de pesquisas. Experiências de sucesso em pomares comerciais também devem ser relatadas visando à promoção de intercâmbio de informações a respeito das práticas culturais, colheita, pós-colheita, processamento e mercados interno e externo.

A alta perecibilidade da graviola é um dos maiores entraves à comercialização da fruta fresca, visto que a distância dos mercados consumidores e o reduzido tempo de prateleira podem ocasionar perdas econômicas elevadas. A grande maioria dos frutos é destinada ao processamento em agroindústrias, para a fabricação de sucos, sorvetes, doces, licores, frutas cristalizadas entre outros. Apesar da importância da graviola em algumas regiões do País, é reduzido o número de levantamentos sistemáticos de sua produção por parte de órgãos oficiais, o que dificulta uma análise mais atualizada e específica a respeito da evolução, comercialização e participação dessa fruta no agronegócio brasileiro (NOGUEIRA et al., 2005), especialmente quando se trata de comercialização do fruto descascado, que não passa pelas centrais de abastecimento. Além disso, as estatísticas são defasadas pelos órgãos oficiais, incluindo-se o IBGE.

No âmbito do mercado interno, a comercialização de graviola ocorre, normalmente, pela aquisição direta de frutas semiprocessadas de produtores e/ou fornecedores independentes, e muitas vezes pelas indústrias de processamento. Pouca é a quantidade de fruta fresca comercializada nas centrais de abastecimento.

Os frutos frescos de graviola comercializados têm como mercados de destino finais, São Paulo, Rio de Janeiro, Salvador, Fortaleza e Brasília. Na região Sudeste, o principal centro de comercialização é São Paulo, onde foram negociadas, em média, 274 t/ano entre 2007 e 2012, de acordo com dados da CEAGESP. Os frutos são ofertados ao longo de todo o ano, sendo que a maior oferta ocorre nos meses de janeiro, abril, maio e de setembro a dezembro. A graviola comercializada nesse entreposto é, em sua maioria, oriunda de lavouras do Estado da Bahia. Em 2012, aproximadamente $88 \%$ da graviola comercializada na CEAGESP foram provenientes dos municípios baianos de Santa Cruz Cabrália, Itabela, Eunápolis e Porto Seguro (CEAGESP, 2013).

Conforme levantamento realizado por Freitas (2012), os produtores da região sul da Bahia (destacando-se Gandu, Nilo Peçanha, Presidente Tancredo Neves, Teolândia, Wenceslau Guimarães, Nova Ibiá e Itamari), principal produtora de graviola do Estado e do Brasil, estão organizados sob a for- ma de cooperativas, associações e sindicatos. Essas organizações visam a facilitar o acesso às infraestruturas coletivas de produção, como câmaras frias, freezers, despolpador, aquisição de insumos, acesso a crédito, bem como a formação de estoques, busca de novos mercados e beneficiamento do produto para agregação de valor. Por meio das cooperativas, alguns produtores conseguem vender graviola para outros estados a preços mais compensadores quando comparados aos preços pagos por unidades de processamento e atravessadores locais.

Observou-se, também, que nessa região o tamanho médio dos pomares com gravioleira é de 3,25 ha, porém foram registrados plantios com áreas de 0,2 até 30 ha e há potencial de expansão do plantio em áreas em cultivo e mesmo em outras localidades da região. Contudo, os produtores locais temem que essa expansão possa afetar a produtividade e o padrão de qualidade de seu produto, além do preço, consequentemente, sua remuneração (FREITAS, 2012).

As variedades mais plantadas na região são Morada, Lisa e Blanca. A Morada tem grande preferência por apresentar menos frutos por planta, mas maiores, o que reduz os custos com mão de obra nas etapas de colheita e ensacamento. As atividades, segundo Freitas (2012), que os produtores mais realizam nos pomares são poda, controle de plantas daninhas, adubação e controle de pragas. Na região, são poucos os produtores que empregam a polinização artificial por acreditarem que a população de polinizadores é suficiente, e dificilmente adotam sistemas de irrigação, também, pois as chuvas, geralmente, são bem distribuídas ao longo do ano.

Segundo Freitas (2012), hipoteticamente, a perda de $10 \%$ dos frutos por atraso na colheita em um pomar, para um tamanho médio de área cultivada de 3,25 ha e produtividade média de $5 \mathrm{t} / \mathrm{ha}$ (a média local é de 5,6 t/ha), proporcionaria uma redução de $1.725 \mathrm{~kg}$ de frutos/ano, significando uma perda de receita de, aproximadamente, $\mathrm{R} \$ 2.240,00 / \mathrm{ano}$, descapitalizando o produtor e, consequentemente, os investimentos na lavoura.

Os mercados de destino são, na sua maioria, as indústrias localizadas nos municípios de Ipiaú, Aurelino Leal, Ibirataia, Feira de Santana, Salvador, Ubaitaba, na Bahia. Alguns produtores conseguiram estabelecer laços comerciais com outros Estados, como Alagoas, Sergipe, Maranhão, Pernambuco, Espírito Santo, Minas Gerais, São Paulo, Goiás e Acre.

As empresas regionais compram de muitos produtores, em lotes de diferentes tamanhos, e algumas são mais exigentes que outras no que diz respeito às boas práticas de produção e qualidade do produto. $\mathrm{O}$ preço pago ao produtor geralmente é menor se 
comparado às indústrias de outros estados e é equiparado ao que é pago pelos atravessadores. Algumas compram mesmo em época de menor demanda e de maior oferta, a fim de fidelizar os fornecedores. Outras empresas diminuem o volume comprado em épocas de baixo consumo, levando o produtor a buscar intermediários para escoar sua produção.

As indústrias de outros estados geralmente compram grandes lotes para compensar o custo do transporte. Alguns produtores possuem volume de produção e capacidade de armazenamento suficiente para comercializar com essas empresas, no entanto são poucos os que conseguem formar lotes individuais, mesmo ao longo de alguns meses, levando-os a comercializar via cooperativa de produtores ou em associações. Esses mercados costumam pagar um preço superior ao praticado na região, despertando interesse dos produtores. Em contrapartida, são mais exigentes no prazo de entrega, qualidade, higiene e padronização da embalagem.

O preço pago ao produtor é diferenciado em função do volume comprado e do mercado de destino, além da qualidade do produto e da localização da propriedade na região. Entre os meses de março e junho de 2011, o preço do fruto descascado oscilou entre $\mathrm{R} \$ 0,60$ e $\mathrm{R} \$ 2,00 / \mathrm{kg}$, com um valor médio de $\mathrm{R} \$ 1,28 / \mathrm{kg}$, na região sul da Bahia. O preço pago ao produtor tem-se concentrado na faixa de $\mathrm{R} \$ 1,10$ a $1,35 / \mathrm{kg}$. Preços acima de $\mathrm{R} \$ 1,70$ têm sido recebidos por produtores que escoam sua produção para outros estados ou indústrias mais distantes do polo produtor, em função da incorporação do frete (custo de transporte). Os preços mais altos ocorreram nos anos de 2009 e 2010 , sofrendo decréscimos a partir do início de 2011.

Observa-se aumento do preço do produto nos mercados do Sudeste, uma vez que a média de preço dos últimos 60 meses na CEAGESP foi de R $\$ 4,27 / \mathrm{kg}$ e, no ano de 2011, foi de R $\$ 4,73 / \mathrm{kg}$ até outubro, sendo que a maior média mensal foi registrada no mês de março de 2011, quando a graviola foi comercializada por $\mathrm{R} \$ 6,06 / \mathrm{kg}$. Na CEASA-ES, o preço médio de comercialização em 2011 foi de $\mathrm{R} \$ 4,41 / \mathrm{kg}$, e a maior média mensal foi verificada em janeiro, $\mathrm{R} \$ 6,12 / \mathrm{kg}$. A CEASAMINAS apresentou a maior valorização do produto no ano de 2011, quando o preço médio mensal foi de $\mathrm{R} \$ 6,46 / \mathrm{kg}$, com a maior média registrada no mês de março, R $\$ 8,57 / \mathrm{kg}$. Já na CEASABA o preço registrado foi bem menor, tendo-se verificado a média mensal de $\mathrm{R} \$ 2,22 / \mathrm{kg}$ em 2011, sendo o mês de dezembro o de maior valorização, quando a fruta chegou a custar $\mathrm{R} \$ 3,00 / \mathrm{kg}$ (Figura 1 ).

É possível que a proximidade entre o mercado atacadista baiano e os produtores reflita em preços in- feriores aos praticados nos mercados mais distantes, em função de maiores custos com frete e impostos, além da lucratividade almejada pelos intermediários para permanecerem na atividade. A maior oferta do produto na região produtora e a possibilidade de compra direta dos produtores, em alguns municípios, devem contribuir para menor valorização da graviola no comércio local. Além disso, a comercialização de frutos in natura nos mercados atacadistas requer uma série de cuidados, como a colheita seletiva de frutos, transporte e armazenamento adequados para a manutenção da qualidade. $\mathrm{O}$ reduzido intervalo de tempo de prateleira do produto, devido à elevada perecibilidade, aumenta os riscos de perdas ao longo da cadeia de produção e de comercialização.

\section{O MERCADO DA PINHA E DAATEMOIA}

As primeiras informações sobre o cultivo da pinha no Brasil datam do século XVII, quando, no ano de 1626, o conde de Miranda introduziu os primeiros pés dessa frutífera no Estado da Bahia. Em função disso, passou a ser conhecida popularmente em grande parte do País como fruta-do-conde.

O clima quente e a estação de chuva bem definida tornaram a região Nordeste uma das localidades mais propícias para o desenvolvimento da cultura no País. No Brasil, atualmente a produção é concentrada na Bahia, especialmente nos municípios de Presidente Dutra, Anagé e Caraíbas, e em Minas Gerais, no município de Jaíba.

A importância socioeconômica da pinheira (Annona squamosa L.) no Brasil tem aumentado nos últimos anos. Seu cultivo comercial tem sido efetuado com maior ênfase na região Nordeste e Centro-Oeste do País, em razão de sua boa adaptação à baixa umidade relativa do ar. Na região Nordeste, a Bahia destaca-se, especialmente a microrregião de Irecê, com cerca de 3.000 ha cultivados, sendo a produção caracteristicamente oriunda de agricultores familiares, pequenos e médios produtores. Nessa microrregião, o município de Presidente Dutra foi batizado como a "capital mundial" da pinha. Outros importantes Estados produtores são: Alagoas, Pernambuco, São Paulo e Minas Gerais.

A oferta da pinha ocorre durante todo o ano nos mercados atacadistas, no entanto há déficit de produção, pois o mercado ainda não consegue suprir a demanda. A concorrência é relativamente fraca, aproximando-se da estrutura perfeita, com a presença de grande número de pequenos produtores. Alguns avanços são necessários, como, por exemplo, melhorar a qualidade do fruto, a pós-colheita e a embalagem. 
Em relação aos preços, esses apresentam oscilação ao longo do ano, resultante da sazonalidade da produção. Normalmente, no segundo semestre do ano, período de entressafra, os preços tendem a ser mais compensadores comparativamente ao primeiro semestre. Dessa forma, cabe ao produtor investimentos no manejo que permitam beneficiar-se desses patamares de preço e aumentar a rentabilidade de seu negócio.

Os produtores de pinha de Presidente Dutra e de municípios circunvizinhos vendem a maior parte de sua produção a intermediários, e estes entregam para os armazéns locais que fazem com que a fruta atinja outras localidades da Bahia e também outros Estados, como Rio de Janeiro, São Paulo e Brasília.

A cultura tem grande relevância socioeconômica local por ser intensiva no uso de mão de obra em algumas etapas da produção, destacando-se a colheita, a poda e a polinização artificial, e a classificação e a embalagem dos frutos. Por muito tempo, as embalagens mais utilizadas eram caixas de madeira; no entanto, pouco a pouco, vêm sendo substituídas por caixas de papelão, que garantem melhor acondicionamento do fruto, facilidade no transporte e tempo de vida útil. Essas embalagens são mais adotadas para mercados mais exigentes, enquanto nos mercados locais da Bahia é comum serem vendidas a granel.

A atemoia tem sido outra anonácea importante no Brasil, especialmente nos Estados de Minas Gerais, São Paulo e, em menor escala, no Paraná e nos estados do Nordeste brasileiro. O Estado de São Paulo conta atualmente com cerca de 1.500 ha plantados com atemoieira. No final da década de 1990, essa mesma área era ocupada com pinheiras, mas estas foram pouco a pouco reduzidas e, atualmente, estima-se que apenas 200 ha são cultivados com a produção de pinha. A substituição dessas anonáceas deve-se ao maior retorno econômico proporcionado pela atemoia em função de sua maior produtividade em relação à pinha e também pelo aumento de seu consumo dia a dia à medida que se torna mais conhecida no mercado.

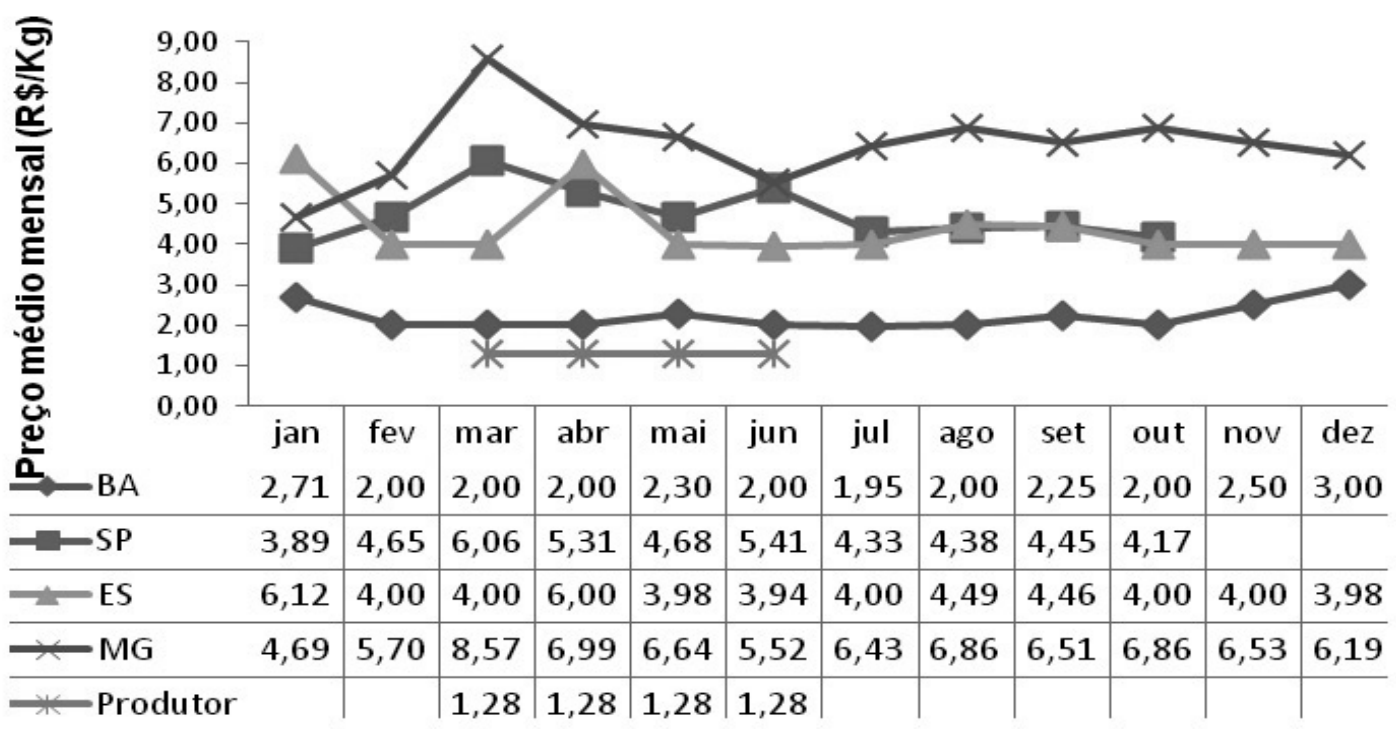

Fonte: EBAL (2011); CEAGESP (2012); CEASA-ES (2012); CEASAMINAS (2012).

FIGURA 1 - Preço médio mensal de frutos frescos de graviola em quatro mercados atacadistas e preço médio pago ao produtor pelo fruto descascado em sete municípios da região sul da Bahia. 
QUADRO 1 - Cultivares comerciais mais importantes dentro do gênero Annona.

\begin{tabular}{|l|l|}
\hline \multicolumn{1}{|c|}{ Espécie } & \multicolumn{1}{c|}{ Variedade comercial } \\
\hline Cherimólia (A. cherimola) & $\begin{array}{l}\text { Whaley, Pink's Mammonth e Mosman (Austrália); Concha Lisa, Bronceada } \\
\text { (Chile); Fino de Jete (Espanha), White, Bays, Golden Russet, Libby e Lisa } \\
\text { (Estados Unidos); Funchal e Mateus I (Portugal), Burton's Wonder e Reretal } \\
\text { (Nova Zelândia), Kabri e Malalai (Israel) }\end{array}$ \\
\hline Graviola (A. muricata) & $\begin{array}{l}\text { Morada, Lisa, Blanca (Colômbia), Gigante de Alagoas, Seleção de Ibimirim, } \\
\text { Cerradina (Brasil) }\end{array}$ \\
\hline Pinha (A. squamosa) & $\begin{array}{l}\text { Red Sugar Apple (Estados Unidos); Noi (Thailândia); Molate e Lobo } \\
\text { (Filipinas), Seleções IPA (Brasil), Cuban Seedless (Cuba); Barbados e } \\
\text { British Guinea; Balanagar e Red Sitaphal (Índia) }\end{array}$ \\
\hline
\end{tabular}

TABELA 1 - Quantidade comercializada (t) e preço (R\$/kg) praticado no CEAGESP, 2008 a 2012.

\begin{tabular}{lccccccc}
\hline & $\mathbf{2 0 0 7}$ & $\mathbf{2 0 0 8}$ & $\mathbf{2 0 0 9}$ & $\mathbf{2 0 1 0}$ & $\mathbf{2 0 1 1}$ & $\mathbf{2 0 1 2}$ & Média \\
\hline \multicolumn{7}{c}{ ATEMOIA } \\
\hline Quantidade (t) & 1.838 & 2.095 & 1.969 & 2.047 & 2.816 & 3.818 & 2.430 \\
Preço (/kg) & 4,46 & 4,53 & 4,33 & 4,24 & 4,85 & 4,22 & 4,44 \\
\hline \multicolumn{7}{c}{ GRAVIOLA } \\
\hline Quantidade ( $\mathrm{t})$ & 228 & 198 & 255 & 296 & 286 & 379 & 274 \\
Preço $(\mathrm{R} \$ / \mathrm{kg})$ & 5,55 & 5,37 & 5,02 & 5,01 & 5,04 & 4,26 & 5,04 \\
\hline \multicolumn{7}{c}{ PINHA } \\
\hline Quantidade $(\mathrm{t})$ & 2.969 & 3.804 & 3.629 & 2.928 & 2.670 & 2.224 & 3.037 \\
Preço $(\mathrm{R} \$ / \mathrm{kg})$ & 5,05 & 5,13 & 5,12 & 4,82 & 4,80 & 4,74 & 4,94 \\
\hline
\end{tabular}

TABELA 2 - Superfície cultivada com gravioleiras em condições de sequeiro por estados mexicanos, em hectares, no período de 2003 a 2011.

\begin{tabular}{lccccccccc}
\hline \multirow{2}{*}{ ESTADOS } & \multicolumn{10}{c}{ ANOS } \\
\cline { 2 - 10 } & $\mathbf{2 0 0 3}$ & $\mathbf{2 0 0 4}$ & $\mathbf{2 0 0 5}$ & $\mathbf{2 0 0 6}$ & $\mathbf{2 0 0 7}$ & $\mathbf{2 0 0 8}$ & $\mathbf{2 0 0 9}$ & $\mathbf{2 0 1 0}$ & $\mathbf{2 0 1 1}$ \\
\hline CAMPECHE & 3,00 & 3,00 & 3,00 & 3,00 & 23,00 & 13,00 & 14,50 & 14,50 & 14,50 \\
COLIMA & 0,00 & 4,00 & 6,00 & 7,00 & 8,00 & 5,00 & 5,00 & 3,00 & 3,00 \\
GUERRERO & 165,00 & 165,00 & 188,00 & 188,00 & 182,00 & 190,00 & 190,00 & 190,00 & 190,00 \\
MICHOACAN & 0,00 & 0,00 & 0,00 & 0,00 & 0,00 & 0,00 & 11,00 & 0,00 & 0,00 \\
NAYARIT & $1.245,50$ & $1.245,50$ & $1.245,50$ & $1.245,50$ & $2.007,05$ & $2.011,50$ & $1.247,00$ & $1.588,50$ & $1.596,85$ \\
PUEBLA & 0,00 & 0,00 & 0,00 & 0,00 & 0,00 & 0,00 & 0,00 & 0,00 & 46,00 \\
TABASCO & 43,00 & 43,00 & 42,00 & 42,00 & 41,00 & 41,00 & 48,00 & 48,00 & 44,00 \\
VERACRUZ & 0,00 & 0,00 & 3,00 & 0,00 & 4,00 & 8,00 & 8,00 & 10,00 & 27,00 \\
YUCATAN & 23,00 & 26,00 & 18,00 & 24,50 & 24,50 & 25,00 & 23,50 & 23,50 & 23,00 \\
\hline
\end{tabular}

TOTAL

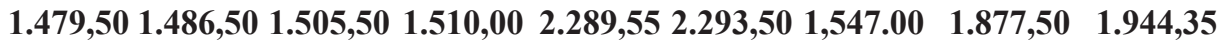

Fonte: SIAP-SAGARPA (2013). 


\section{CONCLUSÕES}

1-As anonáceas apresentam grande potencial de expansão no Brasil e no mundo, especialmente com o desenvolvimento de pesquisas que permitam prolongar o tempo de prateleira dessas frutas, beneficiamento e atingimento a mercados mais distantes das áreas produtivas. Além disso, inúmeros usos têm sido desenvolvidos para a fruta, o que agrega valor e maior rentabilidade da cadeia produtiva.

2-O número de pomar dessas frutas vem aumentando, o que levará à expansão da oferta e, se a demanda crescer em ritmo mais lento, poderá provocar redução de preço no mercado, o que afetará fortemente os produtores, especialmente pela característica familiar da produção e daqueles menos capitalizados. Dessa forma, deve-se pensar em um gerenciamento mais eficiente do negócio rural, a fim de promover o aumento da produtividade com o mínimo de custo possível, bem como a agregação de valor ao produto gerado, possibilitando maiores rendimentos ao produtor e garantia de qualidade para o consumidor. Além disso, são necessárias ações de políticas públicas direcionadas ao setor e que contribuam para o desenvolvimento rural da região.

\section{REFERÊNCIAS}

ADAB- Agência de Defesa Agropecuária do Estado da Bahia. 2010. Disponível em: $<$ http://www.adab. ba.gov.br/modules/news/article.php?storyid $=480>$. Acesso em: 21 maio 2010.

CEAGESP- Companhia de Entrepostos e Armazéns Gerais de São Paulo. 2012. Disponível em: $<\underline{\mathrm{http}} / / /$ www.ceagesp.gov.br>. Acesso em: 10 mar. 2013.

CEASA-ES. Centrais de Abastecimento do Espírito Santo. 2012. Disponível em: $<$ http://www.ceasa. es.gov.br/>. Acesso em: 15 nov. 2012.

CEASAMINAS. Centrais de Abastecimento de Minas Gerais. 2012. Disponível em: $<$ http://www. ceasaminas.com.br>. Acesso em: 15 nov. 2012.

EBAL- Empresa Baiana de Alimentos. Disponível em: <www.ebal.ba.gov.br/novagestao $>$. Acesso em: 28 dez. 2011.
FREITAS, A. L. G. E. de. Caracterização da produção e do mercado da graviola (Annona muricata L.) no Estado da Bahia. 2012. 108 f. Dissertação (Mestrado em Agronomia - Fitotecnia) Universidade Estadual do Sudoeste da Bahia, Vitória da Conquista, 2012.

LIMA, M.A.C.;ALVES, R.E.;FILGUEIRAS,H.A.C.; LIMA, J.R.G. Uso de cera e 1-metilciclopropeno na conservação refrigerada de graviola (Annona muricata L.). Revista Brasileira de Fruticultura, Jaboticabal, v. 26, n. 3, p. 433-437. 2004.

NOGUEIRA, E. A.; MELLO, N. T. C.; MAIA, M. L. Produção e comercialização de anonáceas em São Paulo e Brasil. Informações Econômicas, São Paulo, v. 35, n. 2, p.51-54, 2005.

SIAP-SIGARPA. Servicio de Información Agroalimentaria y Pesquera-Secretaría de Agricultura, Ganadería, Desarrollo Rural, Pesca y Alimentación. Disponível em: http://www.siap. gob.mx/agricultura-produccion-anual/. Acesso em: 12 mar. 2013.

SOBRINHO, R. B. Potencial de exploração de anonáceas no Nordeste do Brasil. In: Semana da Fruticultura, Floricultura e Agroindústria, 17., 2010, Fortaleza. Anais... Fortaleza: Embrapa Agroindústria Tropical, 2010. 